Mitsubishi Tanabe, Nippon Kayaku, Novartis, Pfizer Japan Inc, Taiho, Taisho Toyama, Takeda, Teijin, Consultant for: Astra Zeneca K.K., Eli Lilly Japan K.K., Novartis Pharma K.K., Mitsubishi Tanabe Pharma Co., Asahi Kasei Medical K.K., AbbVie GK, Daiichi Sankyo Co., Ltd., Bristol Myers Squibb, and Nipponkayaku Co. Ltd., Speakers bureau: Astellas Pharma Inc., Bristol Myers Squibb, Chugai Pharmaceutical Co., Ltd., Mitsubishi Tanabe Pharma Co., Pfizer Japan Inc., Santen Pharmaceutical Co., Ltd., Takeda Pharmaceutical Co., Ltd., Teijin Pharma Ltd., AbbVie GK, Asahi Kasei Pharma Corp., Taisho Toyama Pharmaceutical Co., Ltd., SymBio Pharmaceuticals Ltd., Janssen Pharmaceutical K.K., Celltrion Inc., Nipponkayaku Co. Ltd., and UCB Japan, Speakers bureau: AbbVie, Asahi Kasei, Astellas, AstraZeneca, AYUMI, Bristol-Myers Squibb, Chugai, Daiichi Sankyo, Eisai, Eli Lilly Japan, Janssen, Mitsubishi Tanabe, Nippon Kayaku, Novartis, Pfizer Japan Inc, Taiho, Taisho Toyama, Takeda, Teijin, Speakers bureau: AbbVie GK., Bristol-Myers K.K., Chugai Pharmaceutical Co. Ltd., Mitsubishi Tanabe Pharma Co., Pfizer Japan Inc., Astellas Pharma Inc, Diaichi Sankyo Co. Ltd., Eisai Co. Ltd., Sanofi K.K., Teijin Pharma Ltd., Takeda Pharmaceutical Co. Ltd., Novartis Pharma K.K. DOI: 10.1136/annrheumdis-2019-eular.1186

\section{THU0586 CLINICAL CHARACTERISTICS AND RISK FACTORS OF POLYMYOSITIS AND DERMATOMYOSITIS COMBINED WITH INTERSTITIAL LUNG DISEASE IN PATIENTS RESIDING IN THE NORTHEAST SICHUAN PROVINCE IN CHINA}

Zi-Yi Tang, Yu-Feng Qing, Jian-Xiong Zheng, Dan Wang, Ting Yi, Wen-Jun Zhou, Qian Qin. Institute of Rheumatology and Immunology, Affiliated Hospital of North Sichuan Medical College, Nan Chong, China

Background: Idiopathic inflammatory myositis (IIM) is a systemic autoimmune disease characterized by nonsuppurative inflammation of striated muscle, myalgia, and proximal and symmetric muscle weakness. IIM can affect numerous organ systems, such as the skin, lungs, heart, and gastrointestinal tract. Polymyositis (PM) and dermatomyositis (DM) are the most common forms of IIM. Interstitial lung disease (ILD) is a common and severe complication of PM/DM, and concurrent ILD in patients with $\mathrm{PM} / \mathrm{DM}$ is a major cause of death, with a fatality rate that exceeds $50 \%$ [1]. To explore the clinical features and risk factors of PM/DM combined with ILD (PM/DM-ILD)can improve the early diagnosis rate, put early interventions and improve the therapeutic effect.

Objectives: We explored the clinical features and risk factors of PM and $\mathrm{DM}$, combined with ILD to increase early diagnosis and improve treatment outcomes.

Methods: Data were collected from 130 patients with PM/DM, treated at a single center from January 1, 2014 to September 30, 2018. General medical status, clinical symptoms, laboratory indicators, high-resolution computed tomography, therapeutic outcomes, and prognoses were retrospectively reviewed in patients with PM/DM with (ILD group) and without (NILD) ILD. Results: There was statistically significant difference in age between the ILD group ( $n=65)$ and the NILD group $(n=65) \quad(p<0.05)$, but no significant between-group differences in $\mathrm{PM} / \mathrm{DM}$ ratio, sex, or disease duration $(p>0.05$ for all). In the ILD group, initial symptoms were arthritis and respiratory symptoms, and myasthenia for the NILD group. Incidences of Raynaud's phenomenon, dry cough, expectoration, dyspnea on exertion, arthritis, fever, globulin (GLOB), erythrocyte sedimentation rate (ESR), and anti-Jo-1 antibody rate were higher for ILD $(p>0.05$ for all); however, albumin (ALB), creatine kinase aspartate aminotransferase activity ratio (CK/AST) and CK were significantly lower in the ILD group $(p>0.05$ for all). Bivariate logistic regression analysis showed that age, dry cough, arthritis, dyspnea on exertion, anti-Jo-1 antibody, and elevated GLOB were independent risk factors for ILD among patients with PM/DM.

Table 1. Bivariate logistic regression analysis on risk factors associated with ILD in patients with PM/DM

\begin{tabular}{|c|c|c|c|c|c|c|}
\hline \multirow[t]{2}{*}{ Variables } & \multirow[t]{2}{*}{$B$} & \multirow[t]{2}{*}{ SE } & \multirow{2}{*}{$\begin{array}{c}p \\
\text { value }\end{array}$} & \multirow[t]{2}{*}{ OR } & \multicolumn{2}{|c|}{$95 \% \mathrm{Cl}$ for OR } \\
\hline & & & & & $\begin{array}{l}\text { Lower } \\
\text { limit }\end{array}$ & $\begin{array}{c}\text { Upper } \\
\text { limit }\end{array}$ \\
\hline Age & .053 & .018 & .003 & 1.054 & 1.018 & 1.092 \\
\hline Dry cough & .997 & .449 & .026 & 2.71 & 1.125 & 6.592 \\
\hline Arthritis & 1.089 & .481 & .024 & 2.971 & 1.157 & 7.63 \\
\hline $\begin{array}{l}\text { Dyspnea on } \\
\text { exertion }\end{array}$ & 1.192 & .483 & .014 & 3.295 & 1.279 & 8.493 \\
\hline Anti-Jo-1 (+) & 1.517 & .706 & .032 & 4.558 & 1.141 & 18.201 \\
\hline GLOB & .093 & .029 & .001 & 1.097 & 1.036 & 1.162 \\
\hline
\end{tabular}

Conclusion: The morbidity associated with PM/DM-ILD is high. Older age, dry cough, arthritis, dyspnea on exertion, anti-Jo-1 antibody positivity, and increased GLOB increase the risk of developing ILD. This information could be used to carefully monitor changing lung function in these patients.

\section{REFERENCES:}

[1] Lega JC, Reynaud Q, Belot A, et al. (2015) Idiopathic inflammatory myopathies and the lung. Eur Respir Rev 24(136):216-238.

Disclosure of Interests: Zi-Yi Tang: None declared, Yu-Feng Qing Grant/ research support from: Sichuan Youth Science and Technology (2016JQ0053), and the Department of Science and Technology of Sichuan Province (2018JY0257), Jian-Xiong Zheng: None declared, Dan Wang: None declared, Ting Yi: None declared, Wen-Jun Zhou: None declared, Qian Qin: None declared

DOI: 10.1136/annrheumdis-2019-eular.3907

\section{THU0587 COMPARING OF TWO DISTINCT SEVERITY SCORES FOR EVALUATING DISEASE SEVERITY IN FAMILIAL MEDITERRANEAN FEVER}

Emre Tekgoz ${ }^{1}$, Seda Colak ${ }^{1}$, Fatma Illknur Cinar ${ }^{2}$, Sedat Yilmaz ${ }^{1}$, Muhammet Çınar'. ${ }^{1}$ University of Health Sciences, Gulhane Faculty of Medicine, Department of Internal Medicine, Division of Rheumatology, Ankara, Turkey;

${ }^{2}$ University of Health Sciences, Gulhane Faculty of Nursing, Department of Internal Medicine Nursing, Ankara, Turkey

Background: Familial Mediterranean Fever (FMF) is a chronic hereditary disease which is characterized by recurrent attacks of fever accompanied by serositis. Severity of disease is related with morbidities such as amyloidosis and chronic renal failure.

Objectives: The aim of this study was to evaluate disease severity with two disease severity scores in FMF patients, and compare them.

Methods: The study included 160 patients with FMF. Demographic and clinical data were recorded in the patients' form. The patients' disease severity were evaluated with International Severity Scoring System for FMF (ISSF) and The Second Set of FMF severity score (F-SS-2).

Results: A total of 160 patients, comprising of 106 males (66.3\%) and $54(33.8 \%)$ females with a mean age of $33.5 \pm 12.2$ years were evaluated. Mean disease duration was $16.6 \pm 10.3$ years. Other demographic and clinical characteristics of the patients were shown in Table 1. According to ISSF, $67(41.9 \%)$ patients were classified as having mild disease, $80(50.0 \%)$ patients as intermediate disease and $13(8.1 \%)$ patients as severe disease. On the other hand, $59(36.9 \%)$ patients were classified as having mild disease, $41(25.6 \%)$ patients as intermediate disease and $60(37.5 \%)$ patients as severe disease according to F-SS-2 score. Higher rates of patients were found having severe disease according to F-SS-2 compared with ISSF $(\mathrm{p}<0.001)$. Also, lower rates of patients were scored as having intermediate disease with F-SS-2 compared with ISSF $(\mathrm{p}<0.001) \quad($ Table 2$)$.

Table 1. Sociodemographic and clinical characteristics of patients $(n=160)$

\begin{tabular}{|l|l|}
\hline \multicolumn{1}{|c|}{ Characteristics } & \\
\hline Fender, $\boldsymbol{n}$ (\%) & $106(66.3)$ \\
\hline Age (years), mean \pm SD & $54(33.8)$ \\
\hline Disease duration (years), mean \pm SD & $33.5 \pm 12.2$ \\
\hline Age of diagnosis (years), mean \pm SD & $16.6 \pm 10.3$ \\
\hline Delay of diagnosis (years), mean \pm SD & $23.1 \pm 12.7$ \\
\hline Age of symptom onset (years), mean \pm SD & $6.2 \pm 7.9$ \\
\hline Dose of colchicine, (mg/day), mean \pm SD & $16.9 \pm 11.8$ \\
\hline ISSF Score (n, \%) & \\
Mild & \\
Intermediate & $67(41.9)$ \\
Severe & $80(50.0)$ \\
\hline F-SS-2 Score (n, \%) & $13(8.1)$ \\
\hline $\begin{array}{l}\text { Mild } \\
\text { Intermediate } \\
\text { Severe }\end{array}$ & $59(36.9)$ \\
\hline
\end{tabular}


Table 2. Comparison between F-SS-2 and ISSF Score

\begin{tabular}{|c|c|c|c|c|c|c|}
\hline & & \multicolumn{4}{|c|}{$\begin{array}{l}\text { ISSF Score } \\
(n=160)\end{array}$} & \multirow[b]{2}{*}{$p^{a}$} \\
\hline & & Mild & Intermediate & Severe & Total & \\
\hline F-SS-2 & Mild & $37(62.7)$ & 20 (33.9) & $2(3.4)$ & $59(100.0)$ & $<0.001$ \\
\hline Score & Intermediate & $22(53.7)$ & $17(41.5)$ & $2(4.9)$ & $41(100.0)$ & \\
\hline \multirow[t]{2}{*}{$(n=160)$} & Severe & 8 (13.3) & $43(71.7)$ & $9(15.0)$ & $60(100.0)$ & \\
\hline & Total & $\begin{array}{c}67 \\
(100.0)\end{array}$ & $80(100.0)$ & $\begin{array}{c}13 \\
(100.0)\end{array}$ & $\begin{array}{c}160 \\
(100.0)\end{array}$ & \\
\hline
\end{tabular}

F-SS-2: The second set of Familial Mediterranean Fever severity score, ISSF: International Severity Scoring System for Familial Mediterranean Fever, ${ }^{\text {apearson }}$ Chi-Square test

Conclusion: Disease severity scores should be used for treatment choice, evaluation of disease prognosis and classify patients according to disease severity in clinical trials. In the current study, we found a difference between the classifications of disease severity, which could be a result of each scoring system uses different parameters of the disease. Disclosure of Interests: None declared DOI: 10.1136/annrheumdis-2019-eular.3691

\section{THU0588 CLINICAL PHENOTYPES OF IGG4-RELATED DISEASE IN SPAIN}

María Toledano-Macías ${ }^{1}$, Andreu Fernandez-Codina ${ }^{2}$, lago Carballo ${ }^{3}$, Borja De Miguel-Campo ${ }^{4}$, Luis Sáez-Comet ${ }^{5}$, José Hernández-Rodríguez ${ }^{6}$,

Blanca Pinilla ${ }^{1}$, Fernando Martínez-Valle ${ }^{7}$, Registro Español de Enfermedad Relacionada con la IgG4 (REERIGG4) GEAS/SEMI. 'Gregorio Marañón Hospital, Internal Medicine, Madrid, Spain; ${ }^{2}$ Western University, Rheumatology and Internal Medicine, London, Canada; ${ }^{3}$ Hospital Clinico Universitario de Santiago, Medicina Interna, Santiago de Compostela, Spain; ${ }^{4}$ Hospital 12 de Octubre, Internal Medicine, Madrid, Spain; ${ }^{5}$ Hospital Universitario Miguel Servet, Internal Medicine, Zaragoza, Spain; ${ }^{6}$ Hospital Clinic, Autoimmune Diseases, Barcelona, Spain;

${ }^{7}$ Hospital Universitari Vall d'Hebron, Internal Medicine, Barcelona, Spain

Background: Recently, several clinical phenotypes in IgG4-related disease have been described in a multinational and ethnically variate cohort ${ }^{1}$.

Objectives: To assess the clinical presentation of lgG4-related disease (IgG4-RD) in Spanish patients and assess the distribution among different clinical phenotypes.

Methods: Clinical data were obtained from the Spanish IgG4-RD registry (REERIGG4) from October 2013 to December 2018, including 9 centers. We reviewed demographic data and organ involvement. The assignation of clinical phenotypes was done by 2 experts, based on organ involvement and clinical manifestations, following Wallace et al. ${ }^{1}$ subsets. The phenotypes were: pancreato-hepato-biliary (HBP), retroperitoneum and aorta (RA), head and neck limited (HNL) and Mikulicz and systemic (MS). A fifth group designated not defined (ND), included the patients that did not fit in the previous phenotypes.

Results: One-hundred patients were included. Thirty-four (34\%) were females, median age at diagnosis was 54.8 years (IQR 20.7). The ethnicity of the participants was: Caucasian $83 \%$, Hispanic $12 \%$ and NorthAfrican/Middle-East $5 \%$. Ninety-two percent were diagnosed with a biopsy. Regarding the diagnostic criteria, $85 \%$ met consensus pathology criteria and $94 \%$ comprehensive criteria.

Fifty-one patients (51\%) had systemic lgG4-RD involving $>1$ tissue. The most commonly involved tissues were: retroperitoneum (35\%), lymph nodes $(19 \%)$, orbit pseudotumor (18\%), salivary glands (16\%) and pancreas (14\%). Forty-two patients $(42 \%)$ had elevated serum IgG4.

The representation of each clinical phenotype was: HBP 14\%, RA $25 \%$, HNL 26\%, MS $20 \%$, ND 15\%. Patients were equally distributed from the perspective of ethnicity. Men were predominant in all groups $(71,84,70$, $73 \%$ ) except in HNL (61\% for women). Systemic disease was present in all the MS patients, but in $1 / 3$ of the other groups. Serum IgG4 was elevated in $86 \%$ of the cases in $\mathrm{HBP}, 28 \%$ in RA, $19 \%$ in $\mathrm{HNL}, 60 \%$ in MS and $40 \%$ in ND.

Conclusion: The Spanish IgG4-RD population was mainly ethnically Caucasian. Few patients had serum IgG4 elevation. The most frequent phenotype was HNL, followed by RA. The HBP phenotype was less frequent than in previous reports. The influence of race could modify the clinical expression of IgG4-RD. Knowing the regional phenotypes of IgG4-RD may help clinicians improve disease management.
REFERENCES:

[1] Wallace ZS, Zhang Y, Perugino CA, et al. Clinical phenotypes of IgG4related disease: an analysis of two international cross-sectional cohorts. Ann Rheum Dis. doi: 10.1136/annrheumdis-2018-214603

Disclosure of Interests: None declared

DOI: 10.1136/annrheumdis-2019-eular.3725

\section{THU0589 FREQUENCY, CHARACTERISTICS AND CLINICAL DETERMINANTS OF "PRODROME" IN FAMILIAL MEDITERRANEAN FEVER PATIENTS}

Hakan Babaoglu, Nuh Atas, Ozkan Varan, Hasan Satıs, Reyhan Bilici Salman, Aslıhan Avanoglu Güler, Hazan Karadeniz, Berna Goker, Seminur Haznedaroglu, Mehmet Akif Ozturk, abdurrahman tufan. Gazi University Faculty of Medicine, Department of Internal Medicine-Rheumatology, Ankara, Turkey

Background: Prodrome was defined by the presence of manifestations that precede an FMF attack and predict its emergence. This period might be turned to a window of the opportunity for the prompt treatment of impending attacks with fast-acting IL-1 inhibitors.

Objectives: We aimed to determine the frequency, characteristics and clinical determinants of prodrome in patients with FMF

Methods: 401 FMF patients were enrolled in this cross-sectional study. We applied a questionnaire to the FMF patients about attack types, preattack manifestations and latent time. Four hours was accepted as the cutoff point for prodrome as based on the literature, which is compatible with the pharmacokinetics of anakinra.

Results: The mean age was $37.7( \pm 11.0)$ years, and the disease duration was 20 years (3-58). 248 of the patients $(61.8 \%)$ were female. MEFV gene mutations were achieved in $364(90.8 \%)$ patients, of these $121(30.2 \%)$ patients harbored homozygous exon 10 mutations. Patients with a latent time over four hours considered as prodrome positive (PP) patients $(n=141)$. Male gender, homozygous MEFV mutations, peritonitis, pleuritis, arthritis and ELE were more pronounced in PP group. $25.9 \%$ of patients with peritonitis, $14.7 \%$ of patients with pleuritis, $13.2 \%$ with arthritis and $5.5 \%$ with ELE had prodrome with variable latent time durations (median, 6.7(4-72), 6 (4-48), 6 (4-72), and 7.7 (4-30) hours, respectively). Prodrome was found to be more common in those with peritonitis. Male gender, having peritonitis or arthritis were found to be the independent clinical determinants of having prodrome ( $R R 1.72$ (1.07-2.76), $P=0.02$, 4.27 (1.80-10.1), $P=0.001,1.77$ (1.04-3.04), $P=0.04$, respectively). Age, MEFV mutations, pleuritis and ELE were not found as clinical determinants of prodrome.

Conclusion: Especially male patients with peritonitis or arthritis tend to have prodrome more than other patients, and should be questioned. Prodrome positive patients are candidates for prevention of the impending attacks with on-demand treatments.

Table 1. Patients demographics and disease characteristics

\begin{tabular}{lccc}
\hline & $\begin{array}{c}\text { Prodrome } \\
(+) \\
(\mathbf{n = 1 4 1 )}\end{array}$ & $\begin{array}{c}\text { Prodrome }(-) \\
(\mathbf{n}=260)\end{array}$ & $\mathbf{p}$ \\
\hline Age, years & $37.7(10.5)$ & $37.8(12.8)$ & 0.92 \\
Female & $78(55.3 \%)$ & $170(65 \%)$ & 0.05 \\
Age at FMF diagnosis, & $24(3-62)$ & $25(2-59)$ & 0.52 \\
years & & & \\
Disease duration, years & $21(4-58)$ & $19(3-58)$ & 0.08 \\
Fever & 0 & $9(3.5 \%)$ & 0.03 \\
Peritonitis & $133(94.3 \%)$ & $197(75.8 \%)$ & $<0.001$ \\
Pleuritis & $92(65.2 \%)$ & $123(47.3 \%)$ & 0.01 \\
Arthritis & $103(72.9 \%)$ & $129(49.8 \%)$ & $<0.001$ \\
Myalgia & 0 & $6(2.3 \%)$ & 0.09 \\
Erysipelas like erythema & $46(32.6 \%)$ & $58(22.3 \%)$ & 0.02 \\
Homozygous* & $57(43.2 \%)$ & $64(27.6 \%)$ & 0.02 \\
M694V/M694V & $50(35.5 \%)$ & $51(19.6 \%)$ & 0.01 \\
M694V/- & $19(13.5 \%)$ & $46(17.7 \%)$ & 0.19 \\
M694V/M680I & $13(9.2 \%)$ & $23(8.8 \%)$ & 0.98 \\
M694V/V726A & $12(8.5 \%)$ & $20(7.7 \%)$ & 0.88 \\
M694V/E148Q & $6(4.3 \%)$ & $15(5.8 \%)$ & 0.45 \\
M680I/M680I & $6(4.3 \%)$ & $9(3.5 \%)$ & 0.76 \\
\hline * 364 Pationts MEFV mutations & & & \\
\hline
\end{tabular}

* 364 patients MEFV mutations were achieved. $9.2 \%$ of patients MEFV mutations is not known, $7.7 \%$ of patients is gen negative FMF.

Acknowledgement: none

Disclosure of Interests: None declared

DOI: 10.1136/annrheumdis-2019-eular.6550 